NBER WORKING PAPER SERIES

\title{
INDUSTRIAL RELATIONS AND ECONOMIC PERFORMANCE GRIEVANCES AND PRODUCTIVITY
}

Casey Ichniowski

Working Paper No. 1367

\author{
NATIONAL BUREAU OF ECONOMIC RESEARCH \\ 1050 Massachusetts Avenue \\ Cambridge, MA 02138 \\ June 1984
}

The author would like to thank Richard Freeman and Thomas Kochan for their comments on this paper. The research reported here is part of the NBER's research program in Labor Studies and project in Productivity (World Economy). Any opinions expressed are those of the author and not those of the National Bureau of Economic. Research. 
NBER Working Paper \#1367

June 1984

\author{
Industrial Relations and Economic Performance: \\ Grievances and Productivity \\ ABSTRACT
}

This study documents a significant inverse relationship between grievance rates and productivity. It is argued in the theoretical model in the paper that this significant inverse relationship reflects greater discrepencies between reported and effective labor hours as grievance rates increase. A grievance-free plant is some $1.3 \%$ more productive and up to $16.7 \%$ more profitable than when the plant operates with an average rate of grievances, so that industrial relations performance can critically influence the performance of the firm.

Casey Ichniowski

National Bureau of Economic Research 1050 Massachusetts Avenue Cambridge, MA 02138 


\section{INTRODUCTION}

Following on the growing number of studies that document a strong, generally positive link between union status and productivity, 1 a second set of studies has begun to explore the links between economic performance and more specific indicators of industrial relations environments, such as grievance activity, absenteeism, accidents, employee turnover, and strikes.2 'These studies suggest specific dimensions of an establishment's industrial relations system that can influence its performance. Systematic differences along these dimensions between the union and nonunion sector, may, in turn, be the underlying cause of the often observed union productivity differentials.

Among this second set of studies, a common result has emerged. Establishments with high grievance rates perform worse than those with low grievance rates. While it might be hypothesized that this grievance productivity relationship might be positive in some settings, 3 the inverse relationship has been documented in plants in several different manufacturing environments. 4 These studies put forward very similar interpretations for the observed relationships--high grievance rates reflect in some way low morale or poor labor relations 5 and this in turn hinders the establishment's overall efficiency. However, the mechanism by which morale and labor relations affect a plant's efficiency is left unclear due to a lack of data on other productive inputs that would be needed to constmact a more complete model. Here, I also focus on the relationship between grievance activity and 
productivity by analyzing detailed monthly data from January 1976 to September 1982 on the operations of eleven paper mills. Here, however, I test for the relationship in a detailed production function framework with input variables specifically designed to capture the principal sources of productivity variation. Before estimating the production function, I first develop and test a model of the determinants of grievances. From this model, I argue that most causes of grievances will also tend to keep employees from performing work or from putting forth maximum effort while on the job. Using this argument, I then modify the production function to allow higher grievance rates to reflect a greater slippage between hours reported and paid for and effective hours of work. This model then presents a specific mechanism and rationale as to why poor labor relations or low morale, as reflected by grievance activity, might hinder the productivity of an establishment.

The study is developed in the following five sections. The next section develops a model of the determinants of grievance filing. This model is also tested to uncover actual correlates of grievance activity. Section III presents the production function framework which incorporates a role for grievances as an indicator of reduced labor efficiency. Section IV estimates the detailed models of production, and reports the estimated slippage between hours reported and paid for and effective hours of work. The basic model of Section IV is also expanded to include the correlates of grievance activity to see if the observed determinants of trievance rates help account for the inverse grievance-produc- 
tivity relationship. Finally, in Section $V$, by applying the estimated coefficients obtained in Section IV to data on a nonunion mill, I calculate estimates of implied grievance behavior for a nonunion firm. The major results and their implications are summarized in the conclusion.

By way of preview, this study uncovers a significant inverse relationship between grievance rates and a plant's productivity. The magnitude of the grievance rate coefficient implies that a grievance-free firm is $1.3 \%$ more productive and up to $16.7 \%$ more profitable than a firm that operates with an average grievance rate. These differences can be attributed to a $1.8 \%$ difference in labor efficiency between a grievance-free firm and a firm whth an average grievance rate. The nomunion firm behaves as if it has an average grievance rate of .0012 - or twelve times the average grievance rate in the sample of unionized plants. This implicit average grievance rate corresponds to operating $19.5 \%$ below full labor efficiency. In no month does any unionized mill operate that far below full labor efficiency. 
II. THE DETERMINANTS OF GRIEVANCE ACTIVITY

In the ten unionized mills in this sample, grievances proceed through a four-step process: 1) discussion with department foreman; 2) filing the grievance in writing; 3 ) discussions with a comittee on grievances usually involving the labor relations director or mill manager; and 4) arbitration. 'l'he grievance rate in this study is defined as total written grievance filed (step 2) per hourly manhour. With the short time periods between step 1 and step 2 specified in the mills' collective bargaining agreements, the time when a grievance is filed should be close to the time when the original complaint arose. The specific issues of interpretaion that arise from using a grievance rate defined by the grievance activity in step 2 are considered in detail in the theoretical model in this section and the empirical results of the next section. In this sample, the average for this grievance rate variable is .00011 . The lowest mill average is .00001 , while the highest is .00024 . $10.3 \%$ of all mill months are frievance free, while the maximum value is .00098 , or approximately one written grievance for every 1000 production hours worked. The maximum corresponds to a month in which seventy grievances were filed.

To develop an explicit model of the role of grievance rates in determining a firm's performance, one first must understand what causes a grievance to arise. To that end, I develop a model of the determinants of grievances which will be used to generate possible explanations for any observed correlations between grievance rates and productivity. This model of the determinants of 
grievance activity considers three separate paths that can lead to the filing of a grievance.

Path 1: Actual Violations Three steps are required in following this path. First, there is a violation of an accepted practice of the workplace, as specified by clauses in the labor agreement, sidebar agreements, or the cornon law of the shop floor developed through past practices. This violation must then be noticed by an employee or a union representative. The perceived violation may be settled informally and not committed to writing. In path 1 , all three steps are required before a written grievance is filed.

Path 2: Perceived Violations Here, the first of the three steps that make up path 1 is omitted. While no violation actually occurs, one is in fact perceived, perhaps because an employee or union representative does not fully understand the rules of the workplace. If the supervisors can not satisfy the grievant by explaining these rules, a written grievance will result. Since no rule has been violated, it would seem reasonable to expect the probability of informal settlement to be greater in path 2 than in path 1 . This probability in path 2 may still be positive.

Path 3: Strategic Grievances Here again, no violation actually occurs. Employees or their union representatives may find it in their interests to file grievances that they themselves feel are unfounded. Since the filing is strategic, there would be no interest in settling it informally. For example, a disciplinary discharge may be supported by a plant's work rules; however, it is 
relatively costless for the eruployee or the union to file a grievance in hopes that an arbitrator unfamiliar with the plant's rules might reinstate the discharged employee. The union would protect itself asainst charges that it did not represent some employee fairly in this type of case.

Figure 1 presents an overview of the path model. All three paths and the number of steps involved are indicated. To develop this model for empirical testing, specific factors that might influence the stages in this model will be identified.

Specific Factors in the Model of Grievance Activity

An extensive list of factors that influcence the various stages in the path model of grievance filing can be culled from the literature on grievance activity. Slichter, Healy and Livernash, 6 and more recently Lewin7 provide the most comprehensive treatment of the determinants of grievance activity. Their schemes for categorizing these determinants are similar and will be used here. Seven general categories of grievance determinants are presented in their discussions: environment; working conditions; characteristics of the hourly employees; characteristics of management; characteristics of the union; characteristics of the grievance procedure; and the nature of the union-management relationship. I will consider examples of each of these catagories of grievance determinants and where they might fit within the framework of the grievance path model.

Environment. A common consideration here is the size of establishment. 


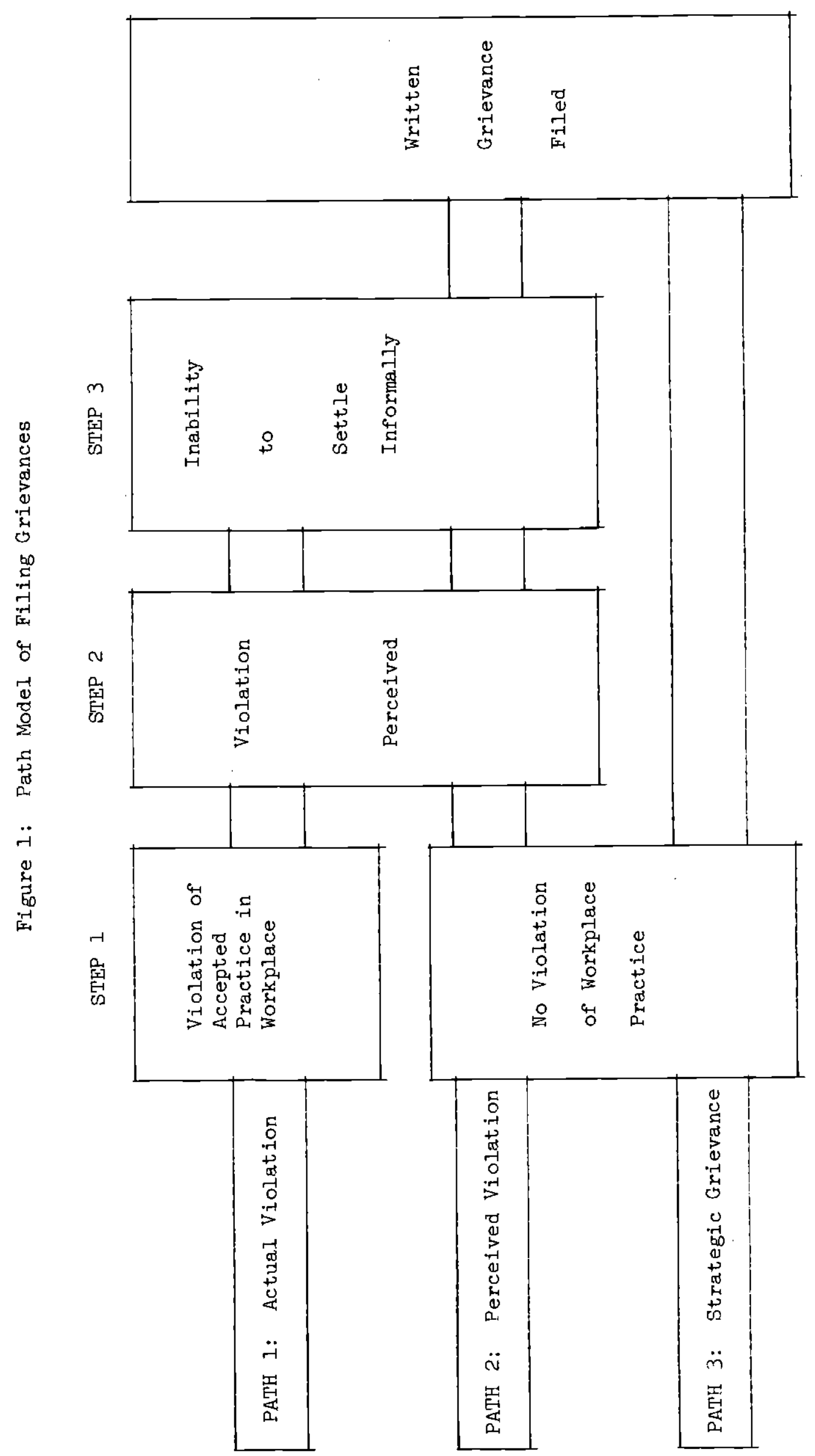


Among steel plants, Peach and Livernash find higher grievance rates in large plants in urban areas.8 Lewin also argues that "a technology that minimizes worker autonomy and maximizes employer control" should lead to high grievance rates.9 Both of these environmental factors could affect grievance rates by increasing the frequency of violations. Larger workplaces tend to have more formal personnel practices.10 This could lower the number of informal settlements; in addition, there might simply be more rules to violate. A more complex technology may also require wore work rules, increasing grievances filed. In this sample technololgy is constant from mill to mill. One mill is sonewhat larger than the rest, but does not, on average have high grievance rates.

Working Conditions. The "environment" category in this context should be thought of as fixed parameters of the workplace (physical location, technology); the "working conditions" category can be thought of as varying features of the work relationship over which the participants have some control. Lewin argues that higher paid workers will file fewer trievances, 11 while slichter, Healy and Livernash find that those on piece-rate are more likely to file grievances.12 Level and method of payment, then, are factors in the model of grievances. The level of corpensation might affect grievance rates by inf'luencing an employee's perception of how equitably he is being treated. A piece-rate method of payment, on the other hand, particularly if it involves incentive and bonus features, may involve more management discretion than a wage rate scheme. Such 
increased discretion may lead to more actual violations (employee paid too little) and more perceived violations (employee perceives he was paid too little).

While the basic technology can be placed in the environmental category, changes in the operation of the plant, such as the introduction of a new machine, might best be considered under working conditions. When changes within the workplace occur, old rules may no longer be appropriate for new situations. Actual violations may increase. Employees may also incorrectly perceive that an old rule applies in the new situation so that perceived violations, where none actually occur, may also increase. Such changes will also affect the likelihood of informal settlements. Cases involving precedents that will govern new situations are the types of cases taken to arbitration.

Finally, the number of work rules should also affect grievance rates; however, the direction of this effect is not necessarily clear. An overabundance of rules, particularly those which conflict, will provide more opportunities for violation and perceptions of violations; however, with an insufficient number of work rules, more situations will be discretionary and lead to more perceived violations that can not be settled informally. Characteristics of Hourly Employees. Low levels of worker satisfaction, as with the pay issues mentioned above, may initiate path 3 . Worker dissatisfaction independent of some workrule or rights violation may lead workers to generate unfounded grievances to burden the employer. In addition, dissatisfied 
workers may be more aware of violations that do occur.

Demographic characteristics of the workforce may also affect grievance rates. An experienced worker, in particular, may be more familiar with the existing mules and therefore be less likely to perceive violations incorrectly. Certain groups such as blacks and women that have historically faced discrimination in the workplace may file more grievances. 13

Management Characteristics. The most often cited feature of plant manarement that affects the orievance rate is front-line supervision. 14 An experienced supervisor may not violate mules as frequently. Certain attitudinal postures of supervisors may cause hourly employees to generate unfounded grievances. Since the foreman is generally the management representative who settles grievances informally, the frequency of informal settlement is clearly affected by the quality, style, and extent of supervision. Finally, management may develop policies that stress either formal or informal settlement. Contract clauses that allow stewards to be paid for time spent processing grievances should lead to more srievances.

Union Characteristics. Establishments with multiple bargaining units should have higher brievance rates with more work rules in place and a greater likelihood of craft-line disputes. Like management, the union may also have specific policies for or against informal settlement of grievances, particularly for specific types of grievances. In particular, a union's policy may be to pursue all discharges as far as possible in the grievance process even if the 
discharge accords with all rules and past practices. In addition, it is often thought that unions strategically generate grievances, regardless of merit, as negotiations approach. Lengthy urievance backlogs can then be used as a bargaining chip in negotiations.

The politics of the union, as well as its policies, may influence grievance rates. More grievances may be generated around the time of union elections as a sign to the rank-and-file that new actions are being taken, particularly if a new officer is elected. Other periods in which there is increased militancy in union tactics may be periods of increased grievance activity. The point is often made that lower grievance rates may reflect fewer problems in the workplace or a "weaker," less militant, union. Lower rates may also result when a union does not police the contract as well, so that violations that do occur may go unnoticed.

Characteristics of the Grievance Procedure. The contract provisions that set out the grievance machinery can also emphasize informal approaches to grievance settlements to varying degrees. Those that do are likely to encourage lower filing rates. In this sample, the grievance procedures are quite similar, so that grievance filing rates should not be affected by this factor.

Union-Management Relationship. It is often argued that more trust may develop as a bargaining relationship matures; conversely, antagonisms may become more ingrained over time. The age of the relationship then can affect the violation rate, perception of violation, and frequency of informal settlement in 
either direction. More than the age of the relationship, it is the quality of the relationship that would seem to matter. A high level of trust between the parties leading to more communication should reduce the grievance rates by influencing all steps in all paths in this model. Moreover, open informal communication should also affect many of the other factors already discussed, such as the number of work rules, employee satisfaction, union politics, and policies of management and the union.

To test the grievance path model empirically, three sets of variables are created to reasure some of the specific factors just described: total labor contract pages in effect; bargaining cycle variables; and variables describing when major machines were installed in these mills.15

Work rules clearly play an important role in the Figure 1 model. The number of pages in a mill's labor contract serves as a proxy for the extent of work rule regulation. (Each mill has three or four different contracts in effect over the seven year period studied.) This proxy for work rules may be misleading. Sidebar agreements not incorporated in the contracts, rules set forth in arbitration decisions, or unwritten shop floor practices will not be captured by this measure. These other sources of work rules may not necessarily increase with contract pages. Still this measure may provide some information on work rules. As described above, a curvilinear relationship may exist between grievances and work rules. Therefore, contract pages and its square will be considered in the analysis. 
The bargaining cycle variables measure whether a mill is in: the quarter leading up to negotiations; the quarter after contract negotiations; the quarter before any negotiations that ended in a strike; the quarter after a strike; and the omitted group of months during the central period of contract administartion. From the preceding discussion, one might expect higher grievance rates prior to negotiations as unions strategically generate grievances. Also, if grievance rates are an indicator of labor-management conflict, grievance rates may increase during bitter negotiations. Conversely, negotiations completed without a strike may lead to a "honeymoon" period of reduced labor-management conflict.

The period in which major machines are installed can involve significant changes in a plant's operations. Jurisdiction disputes over new work nay lead to higher grievance rates. In four mills in this sample, major new machines were installed. Two dumy variables are created to measure the six month installation period and the six month period after the date the machine was capitalized.

When these three sets of variables that are available for all mills are entered in grievance rate equations alons with a set of nine plant dummies, the results in Table 1 are obtained. Columns 1,2 , and 3 show the coefficients when the contract pages, the bargaining cycle variables, and the new machinery variables are entered separately as grievance determinants along with a set of plant dummies. The coefficients in column 4 are obtained when all three sets of 
Iable 1

Correlates of Grievance Filing Rate ${ }^{a}$

[Dependent Variable: Grievances Filed per Hourly Manhour: N=794]

(1)

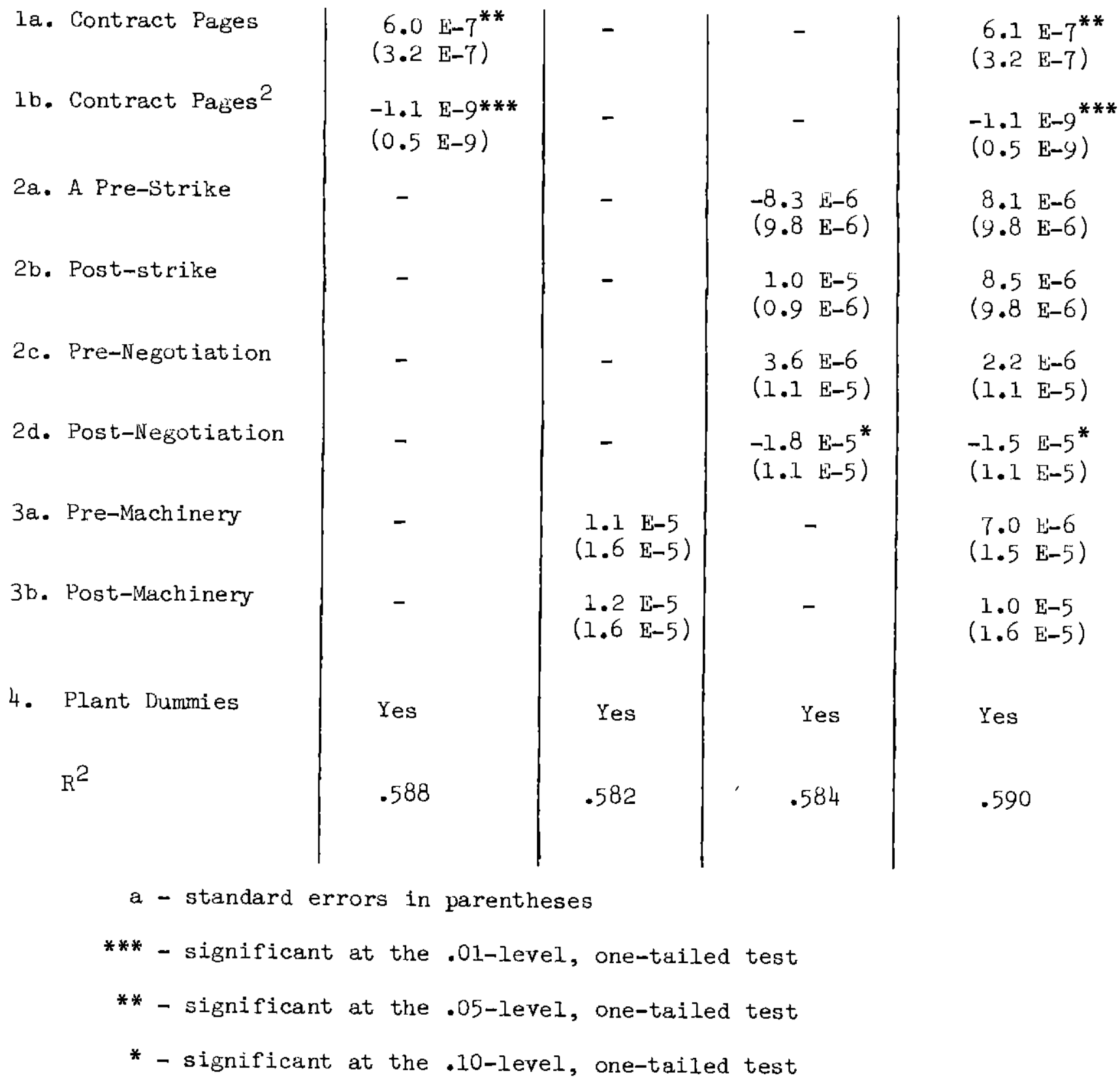


potential grievance determinants are entered simultaneaously. Whether taken one at a time or together, contract pages have the most noticeable impact. The coefficients in line la in columns 1 and 4 suggest that grievance rates are higher when the labor contract in a mill becomes longer. (With plant dummies included, the coefficient gauges the average within-mill relationship. When, the column 4 equation is estimated without plant dummies, the two contract pages coeficients are similar in magnitude but somewhat less significant.) However, from the coefficients in line $1 b$, it appears that grievance rates increase with contract pages at a decreasing rate. Using the coefficients in column 1 , one can calculate the point where grievance rates would begin to decrease with more contract pages. That inflection point occurs at 272 contract pages. The average number of contract pages in the sample is 195; the maximum value for this variable is 465 pages. Therefore, one would want to describe the grievances--contract pages relationship as an inverted $U$. For the range of contract pages in this sample, grievance rates are higher when contracts are longer up to some intermediate value. After that value up to the maximum number of pages, more contract pages are associated with fewer grievances. From the list of possible determinants of grievance activity suggested in the model in this section, contract pages (as a proxy for work rules) appear to be the most critical factor for this set of mills.

Among all other potential grievance determinants, only the quarter after contract negotiations without a strike (line 2d) is shown to have a significant 
partial correlation with grievance rates. The negative coefficient on this post-negotiation variable may by signalling a "honeymoon" period while the parties adjust to new contract provisions after successful contract negotiations. 
III. SPECIFICATION OF THE PRODUCTION PROCESS AND INPUT-OUTPUT DATA

With the aid of on-site investigations of each mill's production process, the production function given by equation 1 was developed to account for variations in productivity in these mills: 16

$$
\begin{aligned}
& \ln Q=\beta_{0}+{ }_{i}^{3} \sum_{1 i}\left(\beta_{1 i} \cdot \mathrm{KD}_{i}\right)+{ }_{i=1}^{9}\left(\beta_{2 i} \cdot \mathrm{KV}_{i}\right)+\sum_{i=1}^{3}\left(\beta_{3 i} \cdot \mathrm{PMD}_{i}\right)+\sum_{i=1}^{4}\left(\beta_{4 i} \cdot\right. \\
&\left.\mathrm{PMV}_{i}\right)+\left(\beta_{5} \cdot E\right)+\left(\beta_{6} \cdot L_{1}\right)+\varepsilon\text { (Equation } 1)
\end{aligned}
$$

Where: $Q=$ tons of physical output;

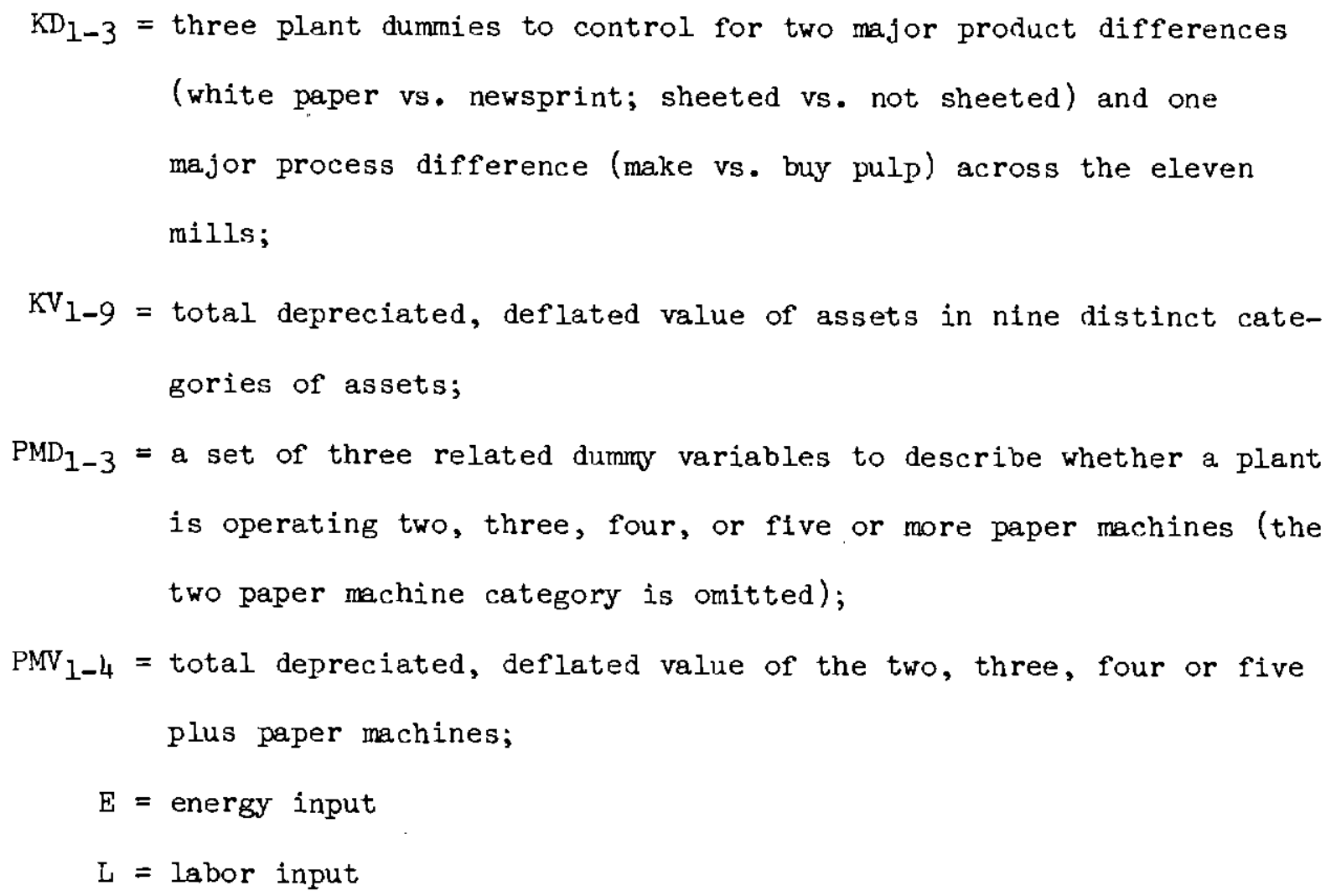

The KD variables provide a direct control for major product and process 
differences observed in these mills. The more conventional method of constructing a value added index is particularly difficult in these mills.17 The PMD variable provides some control over scale of operations. The KV and PMV variables are fashioned to recognize the principles of input aggregation for a heterogeneous capital stock.18 For example, three categories involving enersy generation capital, certain land and buildings, and pollution and recycling capital are not a direct part of the machinery that acts upon the raw materials flowing through the process. These categories of capital, then, are kept separate from other categories of capital that is part of the production process. The capital value variables are constructed from each mill's monthly asset inventory which contains information on the current value of each asset. In any month, there are some 15,000 assets that were allocated to these different categories of capital. E is the natural logarithm of BTU's used in production. The specification of the labor input, $L$, is taken up below. This unconventional specification is developed to provide an accurate model of the production processes in these mills. Equation 1 accounts for over $95 \%$ of the total variation in production in this sample. More conventional functional forms produce several nonsensical coefficients. For example, if all capital is aiggregated into one net investment figure, the coefficient on capital is negative for this set of plants in which capital plays the central role in transforming raw materials into final goods. More conventional forms explain a much smaller proportion of the total variation in output.19 
The specification of labor input and the role of the grievance rate in the equation 1 framework mast now be considered. First, consider that the logarithmic form of equation 1 as a transformation of a simple Cobb-Douglas form: 20

$$
\mathrm{Q}=\alpha \cdot \overrightarrow{\vec{I}^{B}}(\mathrm{EL})^{\gamma} \quad \text { (Equation 2) }
$$

In equation $2, \vec{I} \vec{b}$ reflects a vector of all inputs other than labor described by equation 1 , and kit represents effective hours of labor input. The statistic available to describe labor input in these plants is quite similar to statistics generally available on labor: total hourly manhours reported and paid for (RL). Let $\mathrm{EL}$ be only a fraction of $\mathrm{RL}$, so that:

$$
\mathrm{EL}=(1+\lambda j \mathrm{RL} \quad \text { (Equation 3) }
$$

where $\lambda$ is the negative percentage slippage factor between effective labor hours and reported labor hours.

From the discussion on the determinants of grievances in the previous section, it seems reasonable to conclude that most grievance determinants also keep labor from working or from putting forth a maximum effort. For example, the time spent filing a grievance is paid for but is actually spent away from the employee's work station. Also, when employees file grievances concerning work Jurisdiction, employees are paid for time at the plant while the disputed work is left undone. Other examples described in the previous section can be considered in the same way.

Therefore, let data on the grievance rate (GRV) provide information on the slippage factor, $\lambda$, which can be reexpresed as 0 - GRV. Equation 3 can therefore 
also be reexpressed:

$$
\mathrm{EL}=(1+\delta \cdot \mathrm{GRV}) \mathrm{RL} \quad \text { (Equation } 4)
$$

Substituting equation 4 into equation 2 and taking the natural logarithm of equation 2 , one obtains

$$
\operatorname{lnQ}=\ln \alpha+\vec{\beta} \ln \vec{I}+\gamma \operatorname{lnRL}+\gamma \ln (1+\delta \cdot G R V) \quad(\text { Equation 5) }
$$

For $\gamma \cdot$ GRV small (remember GRV is equal to zero in over $10 \%$ of all observations and has a maximum value of only .00098), equation 5 can be reexpressed:

$$
\ln Q=\ln \alpha+\vec{\beta} \ln \vec{I}+\gamma \operatorname{lnRL}+\gamma \cdot \delta \cdot G R V \quad \text { (Equation 6) }
$$

With the first two terms expanded as in equation 2, the semi-logarithmic specification in equation 6 is the basic model to be estimated in the next section. $\delta$ can be isolated by dividing the GRV coefficient by the RL coefficient. Labor efficiency slippage (the difference between reported labor hours and effective labor hours) can be calculated as $\delta$. GRV for different values of GRV. 
IV. THE PRODUCTIVITY - GRIEVANCE RELATIONSHIP

When the equation 6 specification is estimated, the results in column 1 of Table 2 are obtained. Higher grievance rates are consistently associated with lower plant productivity. In this sample of panel data, this total effect is some combination of cross-and within-plant effects. As described in Section II, the capital dummies (listed in line 3) are actually controls for plant groups. When these dummies are replaced with a complete set of nine mill dummies in the column 2 specification, one observes that the average within-mill correlation between grievances and productivity is still significant and negative. When a set of time dummies ( $\mathrm{s} 1 \mathrm{x}$ year dumies and eleven month dummies) is added to the column 1 specification, the coefficient in column 3 is obtained. This estimate of the cross-plant relationship, while somewhat less significant, is still negative. Across all specifications, the point estimate of the grievance rate is negative.

The magnitude of these generally significant coefficients can be better understood by evaluating them at various levels of the grievance rate variable. Using the column 2 coefficient for this analysis, one obtains the percentage change in a mill's production attributable to movements in this indicator of industrial relations climate.

When the coefficient frorn the column 2 equation (the average within-mill effect) is evaluated at zero, low, average, high, and very high levels of the grievance rate variable (respectively, the minimum, and $25 \mathrm{th}, 50 \mathrm{th}, 75 \mathrm{th}$, and 
Table 2: Grievance Rate Coefficients in the Model

$$
\text { of Paper Productiona }
$$

[Dependent Variable: In Tons of Paper; $\mathbb{N}=531$ ]

\begin{tabular}{|c|c|c|c|}
\hline $\begin{array}{c}\text { Independent } \\
\text { Variables }\end{array}$ & $\begin{array}{c}\text { Equation } \\
1\end{array}$ & $\begin{array}{c}\text { Equation } \\
2\end{array}$ & $\begin{array}{c}\text { Equation } \\
3\end{array}$ \\
\hline $\begin{array}{l}\text { 1. grievance } \\
\text { rate }\end{array}$ & $\begin{array}{r}-.116 .10^{*} \\
(86.13)\end{array}$ & $\begin{array}{c}-126.24 * * \\
(78.94)\end{array}$ & $\begin{array}{c}-89.25 \\
(81.52)\end{array}$ \\
\hline 2. capital dummies & yes & no & yes \\
\hline 3. plant dumnies & no & yes & no \\
\hline 4. time dummies & no & no & yes \\
\hline $\begin{array}{l}\text { 5. other capital } \\
\text { value, enersy, } \\
\text { and hourly man- } \\
\text { hours controls } \\
\text { appearing in } \\
\text { Equation } 1 \text {. }\end{array}$ & yes & yes & yes \\
\hline $\mathrm{R}^{2}$ & .958 & .966 & .966 \\
\hline
\end{tabular}

a - standard errors in parentheses

*** - significant at the .01-level, one-tailed test

** - significant at the .05-level, one-tailed test

* - significant at the .10-level, one-tailed test 
90 th percentiles of the grievance rate distribution), the results shown in Figure 2 are obtained. On average, a move from the zero to the median rate of grievance activity corresponds to a $.79 \%$ drop in a mill's paper production. Moving from the median to the $90 \mathrm{th}$ percentile of grievance activity corresponds to a further $2.56 \%$ drop in production.

These small percentage changes in production can be calibrated in terms of shifts in a mill's profitability. Based on average month in 1980, a one percent drop in production without an associated swing in cost would result in approximately a $12 \%$ loss in operating income. An increase in grievances filed from zero to the highest level would, on average, correspond to a $40 \%$ drop in profits. The recalibration of production losses to losses in profits obviously ignores any costs that might be incurred in reducing grievance activity. Still, these figures do suggest that the shifts in production attributable to movements in this indicator of industrial relations climate can have critical effects on a firm's profitability.

From the labor efficiency model in the previous section, it was argued that these drops in plant production and profitability associated with increases in the grievance rate reflect a slippage between reported labor hours and effective labor hours. To calculate the slippage factor ( $-\mathrm{GKV}$ ), the grievance rate coefficient $(\gamma \cdot \delta$, must be divided by the coefficient on reported labor hours $(r)$. Using the coefficients from equation 2 , one finds that $\delta=$ $-126.24 / .762=-165.67$. For $6 r i e v a n c e-f r e e$ months ( $10.3 \%$ of the sample), the 
Figure 2

GRIEVANCE RATES AND CHANGES IN PRODUCTION

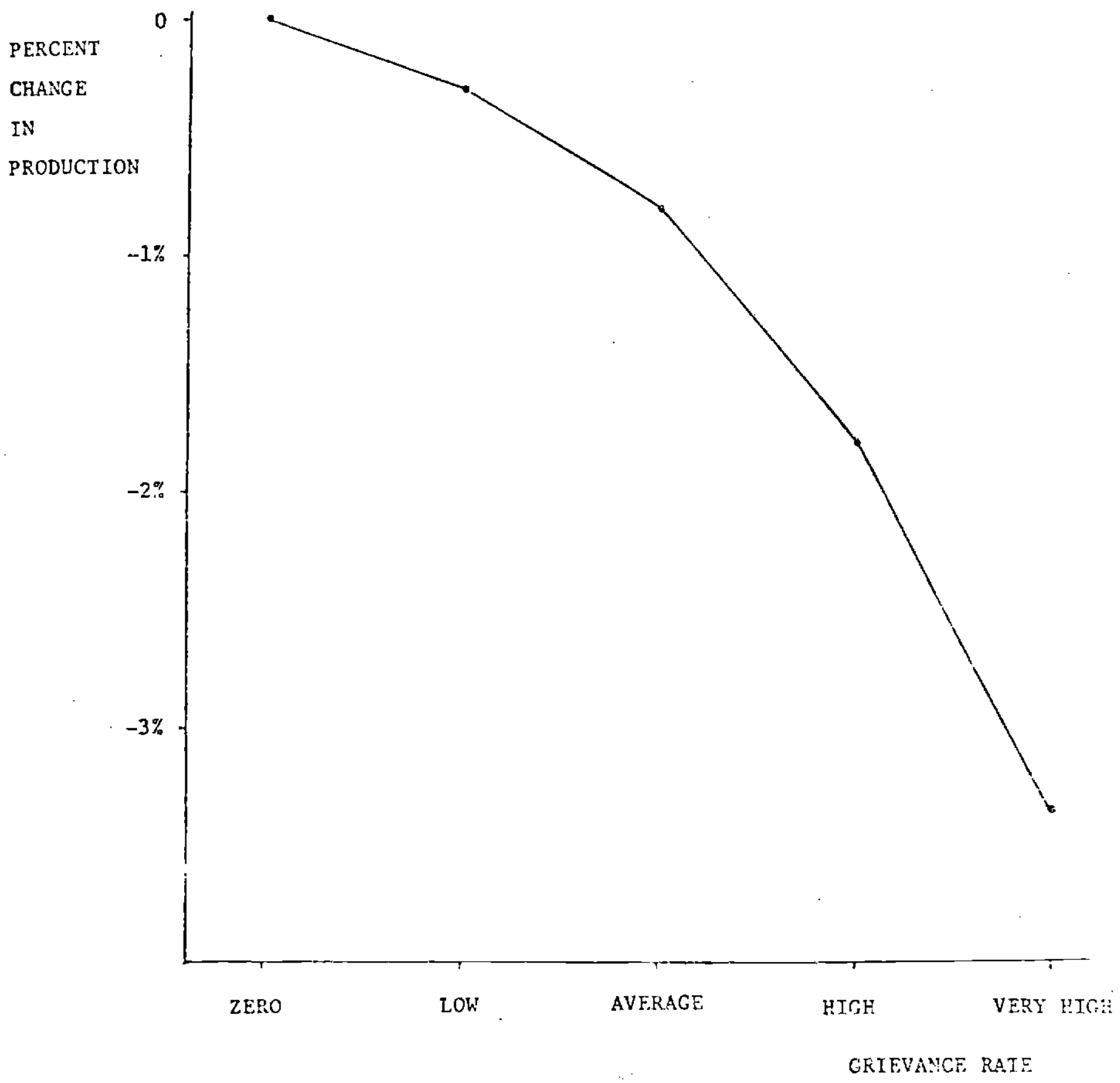


slippage factor $(\lambda=\delta$ - GRV) equals zero. For the average grievance rate (.00011), the slippage factor is $-1.8 \%$. For the maximum grievance rate (.00098), the slippage factor between reported and effective hours of labor is $-16.2 \%$

Further Interpretations of the Grievance-Productivity Relationship

It is unlikely that the type of grievance-productivity relationship reported reflects only those production losses directly associated with time lost in filing and handling grievances. This direct effect of grievance filing on productivity may account for some of the observed relationship, and a rough estimate of its potential magnitude can be obtained. The Table 2 results are based on a sample in which the average number of hourly manhours worked per month is 85,823 . The very high grievance rate (90th percentile) shown in Figure 2 implies production $3.35 \%$ below that of a zero grievance month. This very high grievance rate, .00027 , would mean approximately 23 grievances filed. If the $3.35 \%$ drop in production were strictly the result of an equal drop in production hours worked (or 2,875 hours in an average month), the filing of one grievance would have to take approximately 125 hours to account for the production drop. If each grievance took one hour of employees' time for filing and handling, and if a one percent drop in hours corresponded to a one percent drop in output, this direct effect would account for less than one percent of the production losses attributable to increases in grievance activity.

These simple calculations point out that the observed grievanceproductivity relationship might best be illustrated by the diagram Figure 3 . 


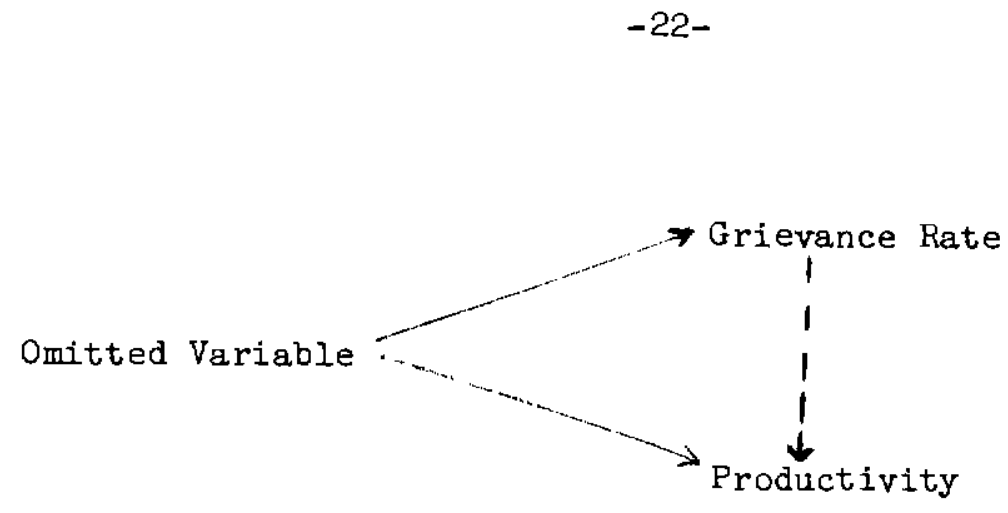

Figure 3

It is likely some oritted factor simultaneously produces high (low) grievance rates and low (high) productivity. The dotted line between grievance rates and productivity could show as a strong negative relationship if the third factor is omitted from the analysis.

The model of srievance filing and the empirical test in Section II suggest several possible candidates for potential omitted variables. Contract pages, in particular, were shown to have a significant curvilinear relationship with grievance rates within mills. Contract pages, as a proxy for work mules, may also be correlated with productivity. The other variables which did not seem to be powerful determinants of grievance rates may still be correlated with productivity. For example, when new machinery is being installed, plant operations may be dssrupted so that productivity is low given the measured level of inputs.

The equations shown in Table 2 are expanded to include those variables that were considered as possible determinants of grievance rates. When the barsaining cycle variables, new machinery variables, and contract pages are 
included in the productivity equation, the results in Table 3 are obtained. Column 1 replicates the column 1 specification in Table 2 with the lone additions of the three sets of grievance determinants considered in section II. Despite several important productivity effects of the new variables, 21 the grievance rate coefficient is almost identical to the coefficient obtained in Table 2. Similarly, the column 2 equation in Table 3 replicates the column 2 equation in Table 2 with the addition of the grievance determinants. Again the grievance rate coefficient is nearly identical in magnitude and significance to the corresponding Table 2 coefficient.

Since the grievance rate coefficient remains negative and generally significant after a number of potential omitted variables are included in the productivity equation, it appears that the grievance rate is still capturing some other unmeasured dimension of the industrial relations environment in these mills. The drop in plant production and labor efficiency corresponding to increases in the grievance rate could not be attributed to any of these specific possible determinants of grievane activity; however, additional insights into the basic result can be suggested by considering the theoretical model of grievance determinants from section II.

Because of the critical role of informal settlements in paths 1 and 2 of the grievance model (see Figure 1), the style of communication in the rills may help explain the inverse grievance-productivity relationship. In these nills, it is important to find out about production delays so that production can flow 
Grievance Rates and Their Correlates in the Production Equation [Dependent Variable $=$ In Tons of Paper; $\mathrm{N}=531$ ]

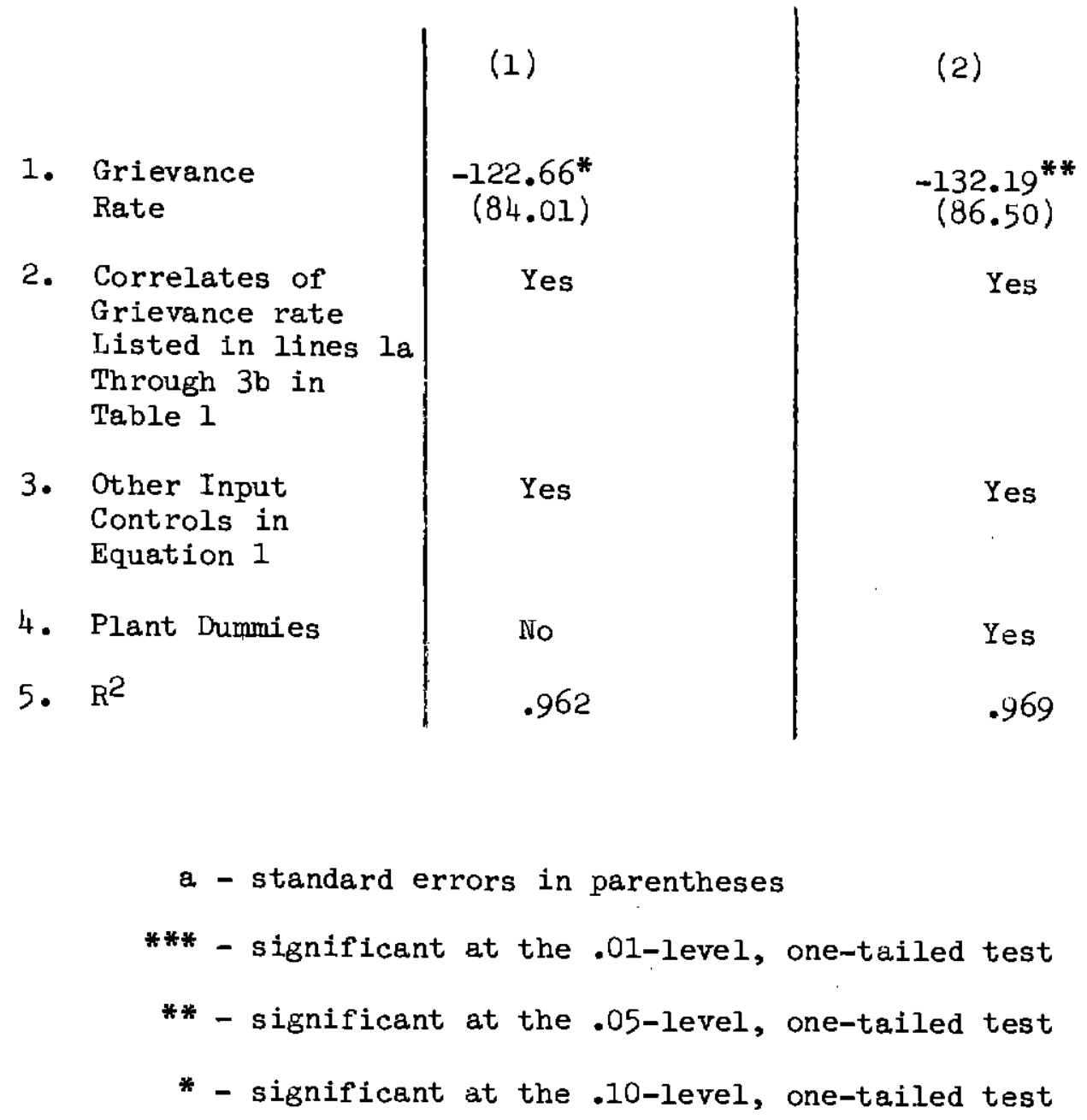


continuously from department to department. Open communication and informal settlements may assist in these coordinating efforts. The role of the foreman as the connection between mill manarers and production ernployees also deserves further attention.22 Still a more detailed analysis of the determinants of grievance activity would be required to provide a more precise interpretation of the inverse relationship between grievance activity and productivity. 
V. THE IMPLICIT GRIEVANCE BEHAVIOR OF A NONUNION FIRM

Monthly data for one nonunion mill are also available in this sample. This mill did not have any grievance machinery and therefore could not be included in the equations estimated in the previous section that required grievance rate information. However, by estimating the basic production function (Table 2, column 1 specification) without a grievance rate variable and with a plant dummy for the nonunion mill, one finds that the nonunion mill is on average $9.5 \%$ less productive than the ten unionized mills given the measured level of inputs. If one also includes time dummies in the equation (corresponding to the Table 2, column 3 specification), the coefficient on the dummy for the nonunion firms is $-14.7 \%$. Both coefficients are significant at conventional levels and are in keeping with the positive union productivity differentials obtained in other studies.

Beyond this conventional analysis one can also solve for the implicit nonunion grievance rates using the nonunion firm's input-output data and the equations estimated in the previous section. Simply the implicit grievance rates for the nonunion mill in each month can be predicted:

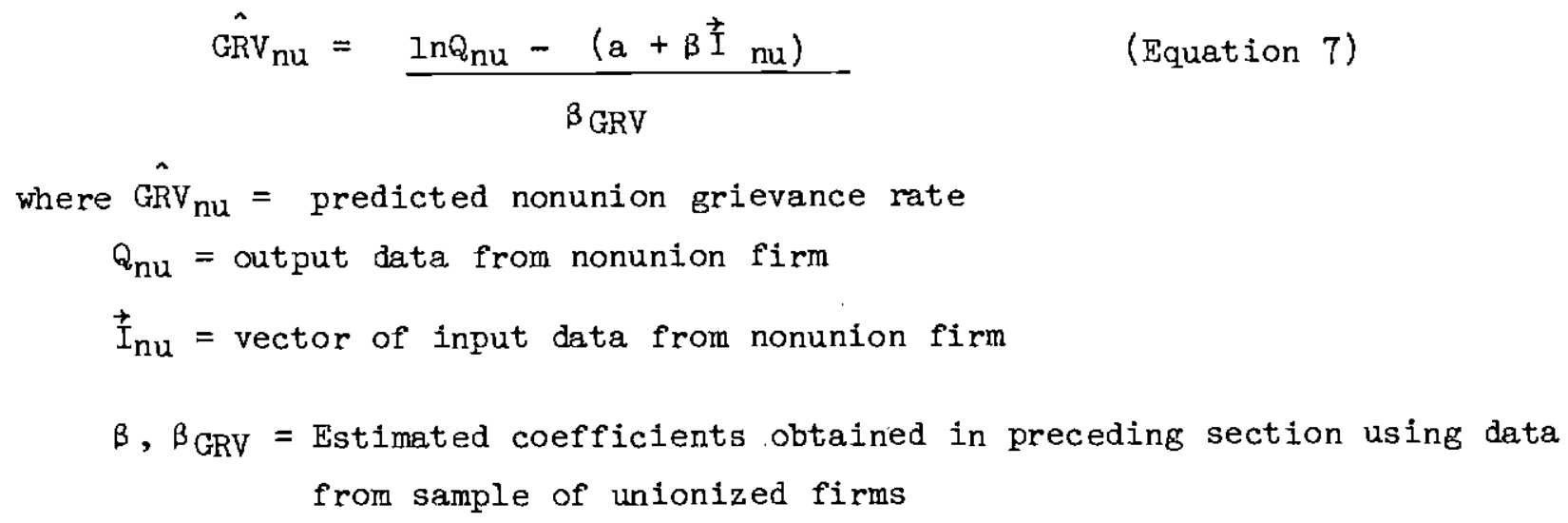


The procedure described by equation 7 makes the strong assumption that the basic productivity equation with the grievance rate variable includes all factors that would account for union/nonunion productivity differences. In other words, the $9.5 \%$ to $14.7 \%$ union productivity differential that remains after controlling for the level of other principal inputs will be attributed solely to higher predicted grievance rates.

When equation 7 is evaluated a grievance rate is predicted for each month for the nonunion mill. The average predicted grievance rate, (using the coefficients from the model in Table 2, Column 1), is .0012 - or twelve times the average grievance rate in the sample of union mills. This average grievance rate exceeds the maximum grievance rate observed in any of the union mills (.0010). This implicit average nonunion grievance rate corresponds to a $19.5 \%$ difference between reported labor hours and effective labor hours. After controlling for the levels of other productive inputs, one finds that labor is utilized in the production process far less efficiently in the nonunion mill than in the unionized mills--consistent with the overall productivity differential between this mill and the ten unionized mills that ranges between -.095 and -.147 .

While other factors ommitted from the basic productivity equation might also be responsible for some of the observed productivity differential, it may not be unreasonable to think of the nonunion mill as having grievance rates significantly higher than those observed in the union mills. Specifically, by not providing the machinery to resolve conflicts or by not having work rules clearly stated and written into a contract, disputes and grievances might linger 
and become exaggerated over time. Regardless of the reason, it seems safe to assume that just because grievances are not written down in nonunion firms, these firms should not be considered to be operating grievance-free. 
VI. CONCLUSION

This unique look at micro-level data suggests that significant links exist between economic and industrial relations performance by documenting a significant inverse relationship between plant production and grievance rates. It is argued in the theoretical model of this paper that this significant inverse relationship reflects greater discrepancies between reported and effective labor hours as grievance rates increase.

The basic empirical results of the paper can be summarized by comparing a mill operating at the average grievance rate to when it operates without grievances. For a given mill, the move from zero grievances to the average grievance rate would correspond to: a $1.3 \%$ drop in mill output; up to a $16.7 \%$ drop in profita; and a $-1.8 \%$ slippage between total reported hours of labor and effective hours labor. Larger increases in the grievance rate would, of course, correspond to even greater decreases in productivity.

In addition, the average production losses attributable to movements in grievance rates over the seven-year period vary from mill to mill. Allowing the zero grievance state to serve as the benchmark, one finds that the mill with the highest average grievance rate had production 6.7 percent below the level of output possible without grievance activity. One mill lost only 0.1 percent of its potential production. The average production loss associated with movenents in grievance rates among the ten unionized mills was 1.7 percent. Furthermore, it is estimated that a nonunion mill in this sample behaves as if it had an 
average grievance rate of .0012 , which corresponds to production 15.1 percent below the grievance-free level of output. This implicit average grievance rate for the nonunion mill in fact exceeds the maximum grievance rate in any of the union mills in any month. While mills with relatively low grievance rates may have devoted more resources toward reducing grievance activity than high grievance mills, these production losses help gauge the economic value of these sorts of efforts. This unique study of plant-level production suggests that significant economic gains can be obtained from improving a firm's industrial relations climate.

Finally, these results suggest certain directions for future industrial relations research. The notion of "good labor relations" should be defined in terms of some objective criterion. Here I select a managerial criterion of productivity. The suggestion that low grievance rates are associated with high levels of productivity indicates that this management-based criterion for good industrial relations performance may not be in conflict with an employee-based criterion; that is, it is reasonable to suspect that low grievance rates also reflect higher levels of employee welfare. A more complete set of determinants of grievances as well as other indicators of a firm's industrial relations environment should be considered as potential determinants of a firm's economic performance. 


\section{FOOTNOTES}

1. For a review of these studies, see Freeman, Richard B. and J.L. Medoff, "Trade Unions and Productivity: Some New Evidence on an Old Issue," NBER Working Paper No. 1249, Cambridge, Massachusetts, (December 1983).

2. Absenteeism, quit behavior, accidents, and strikes are correlated with productivity in Pencavel, John H. "Analysis of an Index of Industrial Morale," British Journal of Industrial Relations, Vol. 12(1), March 1974. Grievance rates, absenteeism and contract negotiations behavior are correlated with an efficiency index in Katz, Harry, T. Kochan, and K. Gobeille, "Industrial Relations Performance, Economic Performance, and the effects of Quality of Working Life Efforts: An Interplant Analysis," Industrial and Labor Relations Review (October 1983); and in Katz, Harry, T. Kochan, and M. Weber, "Assessing the Effects of Industrial Relations and Quality of Working Life Efforts on Organizational Effectiveness," December 1982, Sloan School of Management Working Paper No. 1381-82.

3. One simple hypothesis that would predict a positive grievance-productivity relationship would be that as economic activity in an establishment increases, more grievance activity would be generated, so that the causality would run from production to grievance activity.

4. Katz, Kochan, and Gobeille, and Katz Kochan and Weber document an inverse relationship between grievance rates and plant efficiency in their studies. Also, see Hayes, Robert H. and Kim B. Clark, "Exploring the Sources of Productivity Differences at the Factory Level," Paper presented at the 75th Anniversary Colloquium on Productivity and Technology, March 28-29, 1984, Harvard Business School, Cambridge, Massachusetts. Hayes and Clark document an inverse relationship between grievance rates and a measure of a plant's total factor of productivity for manufacturing plants in several industries.

5. Hayes and Clark argue that increases in grievance rates reflect lower worker morale. See Hayes and Clark, pp. 28-29. Katz, Kochan, and Gobeille and Katz, Kochan and Weber argue in favor of the increased grievance activity reflects poor industrial relations performance.

6. Slichter, Sumner, J. Healy and R. Livernash. The Impact of Collective Bargaining on Management. (Washington, D.C.: Brookings Institution, 1960), pp. 692-720.

7. Lewin, David. "Theoretical Perspectives on the Modern Grievance Procedure," paper presented at New Approaches to Labor Unions Conference, Virginia Polytechnic and State University (October 1981). 
8. Peach, David A. and E.R. Livernash, Grievance Initiation and Resolution: A Study in Basic Steel. (Cambridge, Mass: Harvard University, 1974).

9. Lewin, p. 11 .

10. Eisele, C.F. "Plant Size and Frequency of Strikes," Labor Law Journal 21 (December 1970), pp. 779086; Shorey, John. "The Size of the Work Unit and Strike Incidence," Journal of Industrial Economics 23 (March 1975), pp. $175-88$.

11. Juewin, p. 12 .

12. Slichter, Healy, and Livernash, p. 702 .

13. Lewin, p. 11 .

14. See for example: Fleishman, Edwin A. and Edwin F. Harris, "Patterns of Leadership Behavior Related to Employee Grievances and Turnover,"

Personnel Psychology 15 (Winter 1962), pp. 43-55; Peach, David A. "Union and Management Decision-Making in the Grievance Process," Relations Industrielles 27 (Fall 1972), pp. 757-67; Stagner, Ross. "Personality Variables in Union-Management Relations," Journal of Applied Psychology 45 (October 1962), pp. 350-357.

15. For a smaller sample of observations, data on two labor turnover measures, quit and discharge rates, were also collected as potential correlates of grievance activity. Neither obtained consistently significant coefficients in grievance rate equations.

16. Ichniowski, Casey, "Micro Production Functions Aren't Pretty: Firm-Level and Industry-Level Specification for Inputs and Outputs." NBER Working Paper No. 1365, Cambridge, Massachusetts, (June, 1984), pp. 6-16.

17. Ibid., pp. 8-11.

18. Ibid., pp. 11-13.

19. Ibid., pp. 19-21.

20. While it is not precisely correct to consider the input specification for capital in equation 1 as being derived from the Cobb-Douglas form (see Ichniowski, p.22), this representation does provide a useful illustrative framework for considering the role of grievances in the production process. The specification of the labor input in equation 1 is in fact a direct lntransformation of the specification for labor in equation 2. 
21. These productivity effects of the correlates of grievance rates, particularly contract pages, are being explored in greater detail in current research.

22. A plant-level union productivity study also suggests that the role of formen is critical in the productive operation of firms. See Clark, Kim, "The Impact of Unionization of Productivity: A Case Study," Industrial and Labor Relations Review, Vol. 33 (July 1980), pp. 462-467. 